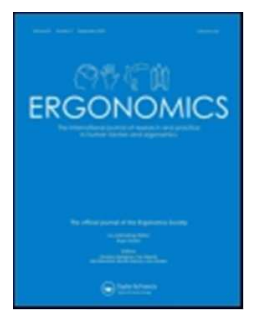

\title{
Quantum Ergonomics: Shifting the Paradigm of the Systems Agenda
}

\begin{tabular}{|r|l|}
\hline Journal: & Ergonomics \\
\hline Manuscript ID & TERG-2015-0129.R3 \\
\hline Manuscript Type: & Special Issue Paper \\
\hline Date Submitted by the Author: & $\mathrm{n} / \mathrm{a}$ \\
\hline Complete List of Authors: & $\begin{array}{l}\text { Walker, Guy; Heriot Watt University, School of the Built Environment } \\
\text { Salmon, Paul; Monash University Accident Research Centre, MUARC } \\
\text { Bedinger, Melissa; Heriot-Watt University, } \\
\text { Stanton, Neville; University of Southampton, School of Civil Engineering } \\
\text { and the Environment }\end{array}$ \\
\hline Keywords: & $\begin{array}{l}\text { general ergonomics < Application Domains, ergonomics tools and methods } \\
\text { < Methods and Approaches, intervention effectiveness < Methods and } \\
\text { Approaches, complex systems < System Performance, socio-technical } \\
\text { systems < Organisational Ergonomics }\end{array}$ \\
\hline \multicolumn{2}{|l}{} \\
\hline
\end{tabular}




\title{
Quantum Ergonomics: Shifting the Paradigm of the
}

\section{Systems Agenda}

\author{
Dr Guy H. Walker, Heriot-Watt University, Edinburgh \\ Prof Paul Matthew Salmon, University of the Sunshine Coast, Queensland \\ Ms. Melissa Bedinger, Heriot-Watt University, Edinburgh \\ Prof Neville A. Stanton, University of Southampton
}

\begin{abstract}
A paradigm is an accepted world view. If we do not continually question our paradigm then wider trends and movements will overtake the discipline leaving it ill adapted to future challenges. This Special Issue is an opportunity to keep systems thinking at the forefront of ergonomics theory and practice. Systems thinking prompts us to ask whether ergonomics, as a discipline, has been too timid? Too preoccupied with the resolution of immediate problems with industrial-age methods when, approaching fast, are developments which could render these operating assumptions an irrelevance? Practical case studies are presented to show how abstract systems problems can be tackled head-on to deliver highly innovative and cost-effective insights. The strategic direction of the discipline foregrounds highquality systems problems. These are something the discipline is well able to respond to provided that the appropriate operating paradigms are selected.
\end{abstract}

Keywords: paradigms, systems thinking, big data, internet of things 


\section{Practitioner Summary}

High quality systems problems are the future of the discipline. How do we convert obtuse sounding systems concepts into practical interventions? In this paper the essence of systems thinking is distilled and practical case studies used to demonstrate the benefits of this new paradigm.

\section{Introduction}

According to the Oxford English Dictionary a paradigm is a "conceptual or methodological model underlying the theories and practices of a science or discipline at a particular time; (hence) a generally accepted world view" (www.oed.com; 2015). But how often do we really scrutinise the paradigm we are operating under? For most people, indeed, for most scientific subjects, the view of the world may as well 'be' the world, so pervasive and unquestioned it is. Looking at paradigms, let alone changing them, is difficult yet we argue necessary (Stanton, Salmon and Walker, 2015). Woods and Dekker (2000), Hancock (1997), Rasmussen, 1997; de Greene (1980), Lee (2001), Guastello (2002), Walker et al. (2010), Dul et al. (2012), Chung and Shorrock (2011) and many others are already questioning the existing paradigm and the need for it to adapt. Still others, like Rifkin (2014), Miller (2015), Marcovici (2014) and Kellmereit and Obodovski (2013) are going further still. Like Toffler in the 1980's $(1980,1981)$, they are suggesting this is a critical moment in history. A moment when infrastructures like the internet are creating a form of globally connected nervous system, when more 'things' will be connected to the internet than 'people' (hence the term 'Internet of Things') which, in turn, will give rise to enormous 
stores of 'big data' measured in zettabytes $\left(10^{\times 21}\right)$ and growing all the time. Hitherto impossible ergonomic insights then become manifest in radically new ways (Walker \& Strathie, 2016; Drury, 2015). In terms of paradigms it is instructive to consider that for most of the post-war period the paradigm in the human sciences has been empirical falsification of the Popperian school, and the generalizability of findings derived from smaller samples to larger populations. This is the microscope through which we extract the majority of meaningful ergonomic insights and develop solutions to real-world problems. Could that be about to change? At least one social science journal has recently made it policy to ban null hypothesis significance testing from all future papers (Trafimow \& Marks, 2015); a bold and possibly significant move. It seems to indicate that in the new paradigm our entire population becomes our sample, and Big Data becomes the 'macroscope' (not 'microscope'; Rifkin, 2014) through which radical new insights could be discovered. Ergonomists are already involved in projects and activities related directly to these challenges (e.g. Sharples et al. this issue) and this Special Issue on New Paradigms is therefore timely. Rather than representing problems that are scattered around the periphery of our discipline these deeply 'systemic' challenges, and the paradigm shifts necessary to cope with them, will become more rather than less central (Dul et al., 2012). This paper will put forward a selection of ergonomic problems emblematic of these paradigm shifts, illustrate some of the key issues in play, and show the methods used to drive out practical insights. It is hoped the discussion will provoke deeper thought about our often unquestioned operating assumptions and how they may need to shift further in future. 


\section{The Quantum World of Ergonomics}

Quantum physics - at the most basic level of explanation possible - is the idea that fundamental properties change at different scales of analysis. Key concepts include Heisenberg's uncertainty principle, in which the more one property is known, the less it is possible to know another property. Bohr's complementarity principle, and the duality that exists when items exhibit contradictory properties simultaneously. And Schrodinger's equation, which helps to define the degrees of freedom that a system time-evolves within. Stated in exceedingly crude terms, quantum physics is about understanding what these different states are, how jumps are made from one state to another, how quantum systems evolve over time, and how nano and macro-scale system behaviours are related. Its influence, as a mode of thought, has expanded far beyond the narrow confines of Physics. It has shifted the wider scientific paradigm in terms of epistemology (making our knowledge of physical reality more probabilistic in nature) and ontology (creating the possibility of multiple valid positions on reality). By crude analogy to quantum physics, therefore, we can legitimately ask whether our own Ergonomic raw material, the 'atoms' and 'particles' of tasks, agents, functions and people (and the rest) can also simultaneously exhibit more than one property? The question then becomes what we choose to abstract from those situations. Different practitioners will observe different properties. Constraining one property experimentally may reduce our ability to measure others. A focus on the nano-scale of ergonomics problems may in turn lead to a loss of perspective on the macro-scale of entire sociotechnical systems. There follow three 'quantum case studies' which, between them, help to meet the paper's two main objectives. Firstly, to remind ourselves that ergonomics is well equipped to cope with systems challenges and they have been spoken of frequently in the past. 
Secondly, to reinforce the idea that systems approaches are practical and usable, not merely abstract or theoretical. Framing these two objectives within the notion of 'quantum ergonomics' provides a contemporary language for advancing an agenda for more systems thinking and more value to be extracted from ergonomic endeavours.

\section{Catastrophic Counter-Intuitiveness}

Ergonomics science is not quantum physics, but ergonomic problems can certainly exhibit what we might loosely label 'quantum behaviour'. That is, systems have many different realities depending on the level of analysis, and elements of the system can indeed exhibit 'complementarity', being simultaneously one thing and another. There is certainly a duality between nano and macro-scale phenomenon as the following study amply demonstrates.

The ergonomic case-study in question centred on road freight and logistics, and the use of vehicle telematics to help reduce carbon emissions (see Walker \& Manson, 2014). Telematics works at the interface of road vehicles and the road network, helping to ensure the former make the most efficient and rational use of the latter. We know from the literature that the shape and topology of a network is a strong contingency factor in how it will perform (Leavitt, 1951; Pugh et al., 1968; Watts \& Strogatz, 1998 etc.) yet behavioural issues like these are rarely embedded in studies of driver behaviour. It is far more common to extract the problem (the driver and the technology) from the network, place them (and them alone) in a driving simulator or other lab-based study for analysis, then reinsert them once the solution has been applied, all on the tacit assumption that the whole will be no more or less than the 
sum of its parts. This is a crude and perhaps unfair classification, but it is born out in the widespread engineering assumption that more technology, more route guidance, and the greater the driver's knowledge of the wider traffic conditions, the better the network will perform (e.g. Nijkamp, Pepping \& Banister, 1997). In other words, all it requires is for people in the system to behave in the correct way. A radical alternative is to use an agent-based approach called traffic microsimulation, create virtual models of entire towns and cities, populate them with thousands of virtual vehicles each exhibiting ergonomically referenced behavioural patterns, run the models many times each, and analyse the probabilistic behaviour of the entire traffic network as it evolves over time. The output from running these microsimulations is a set of raw data for each individual vehicle (out of anywhere between 3000 and 6000 total vehicles) as it progresses through the network. Microsimulation calculates the positional coordinates of each individual vehicle every half a second. This data can then be combined with specific vehicle 'drive cycles' to calculate fuel use and emissions, alongside a wide range of other performance metrics. This constitutes 'big data' compared to the samples more typical under the empirical paradigm common in the ergonomics discipline. 


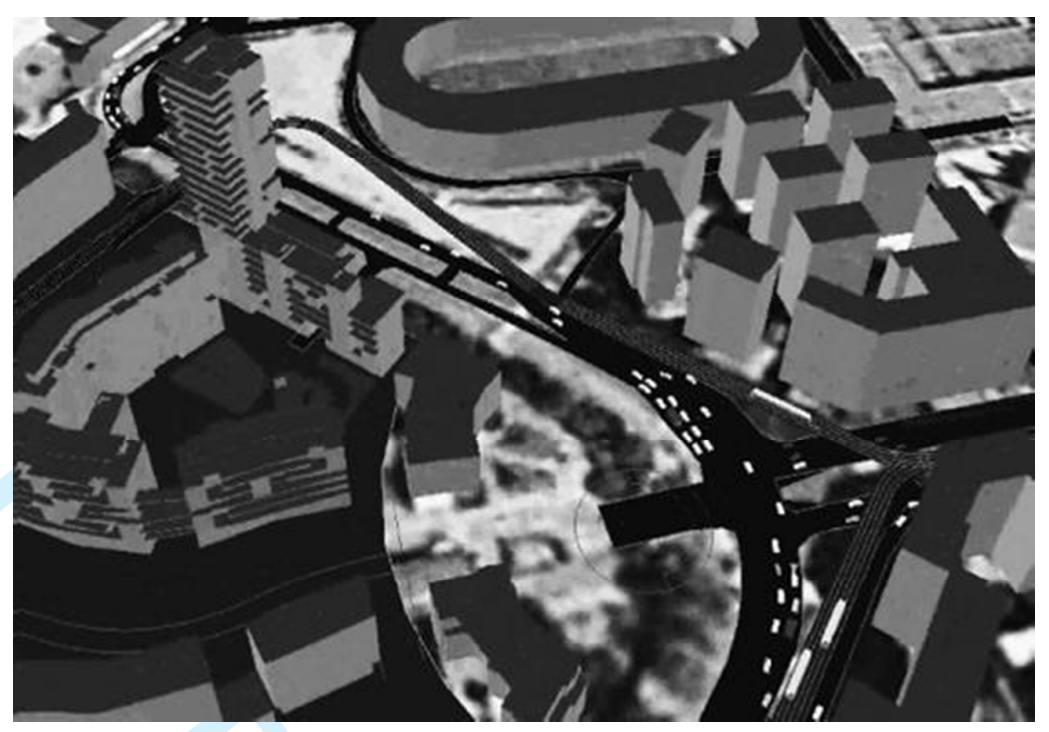

Figure 1 - Agent-based traffic microsimulation software allows the effect of nano-scale individual driver behaviours to be analysed in terms of macro-level global effects on the network.

In this study four real-life towns and cities were modelled, each possessing a distinct network topology. Three types of virtual drivers were set free in the different networks; $50 \%$ without any route guidance, $25 \%$ with route guidance that was only acted on half of the time, and $25 \%$ who followed their route guidance instructions explicitly. The simulation worked by communicating live network information to the virtual drivers (such as queue lengths, link delays, traffic densities) with the virtual drivers seeking more optimum routes through the network in the proportions given above (i.e. presented with this information and a route choice to be made, the virtual drivers would make a positive, optimising choice $0 \%, 25 \%$ or $50 \%$ of the time). In this case optimum performance relates to network performance, and the optimum balance of journey times, emissions and costs. Stakeholders in this study assumed, like much of the literature, that the more route guidance that was provided (and the more it was adhered to) the better the network would perform. This was not the case in practice. 
On some networks, vehicles with route guidance they followed strictly did no better than those drivers who had nothing. On other networks, the investment in more telematics, and enforcing its use, would have sharply diminishing returns (e.g. Figure 2). The detailed findings are contained in Walker and Manson (2014) but the overriding point is that highly rational empirically derived solutions at the individual level can translate into highly dysfunctional outcomes at the level of the total system. In other words, the nano-scale of individual behaviours diverges from the macroscale of overall system behaviours, and moreover, this is not always captured using existing state of science approaches in ergonomics.

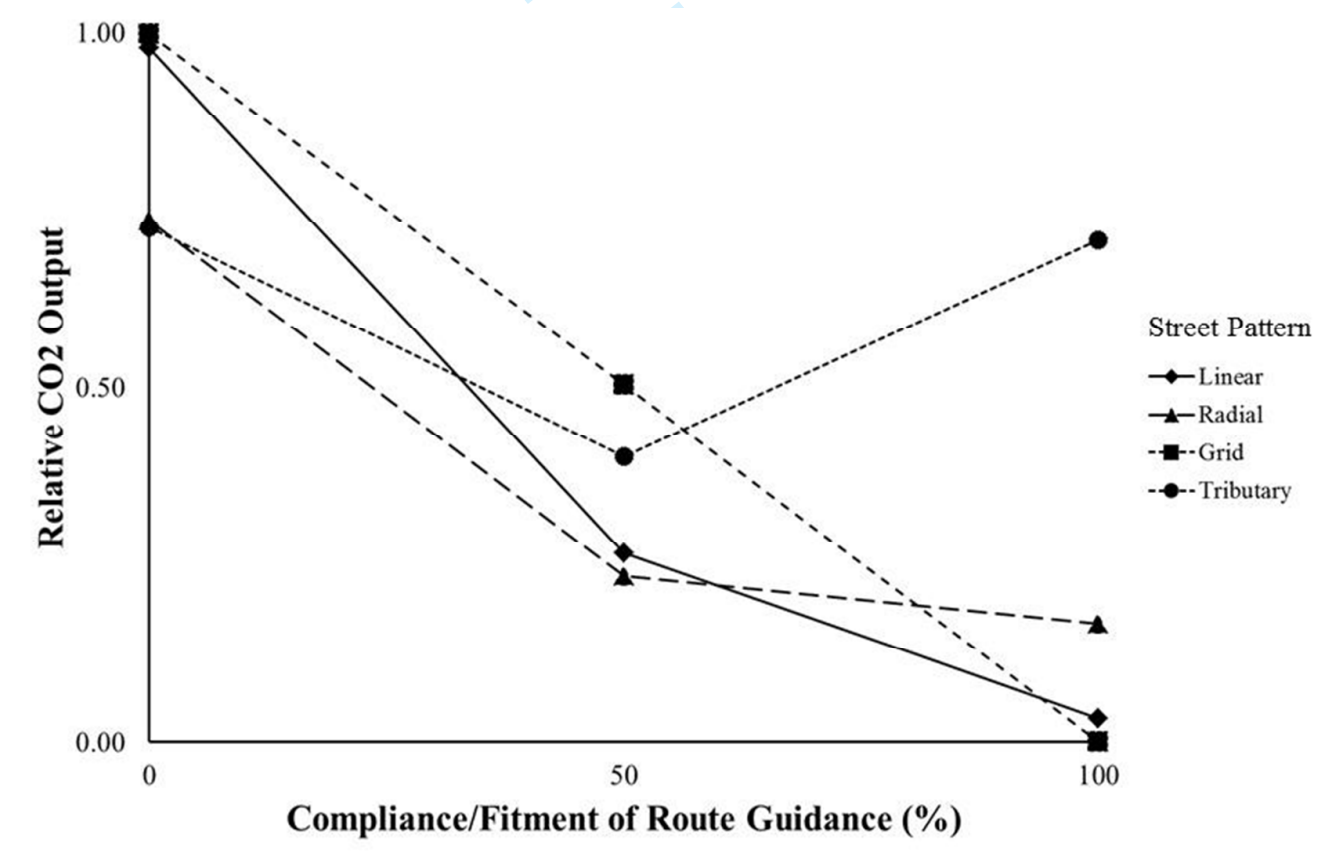

Figure 2-More route guidance at the nano-scale of individual vehicles is not always associated with lower $\mathrm{CO} 2$ emissions at the macro-scale of the entire traffic network: sometimes the reverse.

\section{Everything is a network}


Systems thinking is a framework for conceptualizing or viewing the world as a set of interrelated elements (Carvajal, 1983; Hall \& Fagen, 1956). There is some confusion about how this term is used because there are different types of system and they do not all mean the same thing. People refer to systems methods when they are, in fact, referring to a particular 'type' of system. It is possible to argue that all ergonomics methods are systems methods, because it is entirely possible to have 'sets of interrelated elements' that act as highly deterministic closed systems, ones in which the input, processing, output characteristics of each node are well understood, as are the properties and flows occurring on the links between them. Systems thinking, however, also refers to open systems, and not all systems methods cope equally well with open systems problems. One could argue that in common usage within ergonomics the term 'system' is really referring to 'open system' (Walker et al. 2010). An open system "may attain (certain conditions presupposed) a timeindependent state where the system remains constant as a whole...though there is a constant flow of the component materials. This is called a steady state" (Bertalanffy, 1950, p. 23). Steady state behaviour means that open systems can "grow by processes of internal elaboration. They manage to achieve a steady state while doing work. They achieve a quasi-stationary equilibrium in which the enterprise as a whole remains constant, with a continuous 'throughput', despite a considerable range of external changes." (Trist, 1978, p. 45). This is why 'open systems methods', as distinct from a more general class of methods often labelled as 'systems-based', tend to foreground structure. “...the set of relations [between system elements] determines the very character of the system...[and]...the structure of the system determines its function" (Ropohl, 1999, p. 4). Metcalfe's Law reinforces this point: "as the number of [parts in a system] increases linearly the 
potential 'value or effectiveness' of the [system] increases exponentially” (Alberts, Garstka \& Stein, 1999). Structure is a discoverable aspect of systems, even highly complex open-systems, and it can provide powerful clues as to how the system will behave. This feature can be revealed in the following case study examining how nuclear hunter-killer submarines return to periscope depth (Stanton, 2014).

This is a system comprised of many interacting social and technical elements, one that requires a constant throughput of energy, information, actions and other inputs in order to remain as a coherent entity. One that is able to respond to its environment and change and adapt. Figure 3 illustrates a composite network of task, social and information networks extracted via a method called EAST (Event Analysis for Systemic Teamwork; Stanton \& Bessell, 2008). From this structural representation alone, created via existing ergonomic methods such as Hierarchical Task Analysis (Annett et al., 1971), Social Network Analysis (e.g. Monge \& Contractor, 2003; Driskell \& Mullen, 2005) and semantic networks (e.g. Ogden, 1987), it was possible to discern exactly what was going on between the submarine's on-board sound and control rooms, and how submariners shared information related to the tasks they were performing. 
Seemingly abstruse network representations like that shown in Figure 3 translate into significant practical outcomes. One of these is a full scale submarine simulator facility (see Figure 4) in which alternative structural configurations of task, social and information networks can be systematically tested with real submarine crews to examine their effects on performance, and the system remodelled again in network terms. These insights were simply not available or tractable according to the previous operating paradigms, which were either based around empirical cognitive psychology (highly resource intensive multi-measure, multi-factorial experiments) or loose, single case study analyses (from which only loose and unsystematic insights could be derived). Instead, by focussing on the structural aspects of systems and viewing key features of performance as networks, a powerful new approach 
emerged. This, in turn, is leading directly to significant operational changes on new classes of hunter-killer submarine.

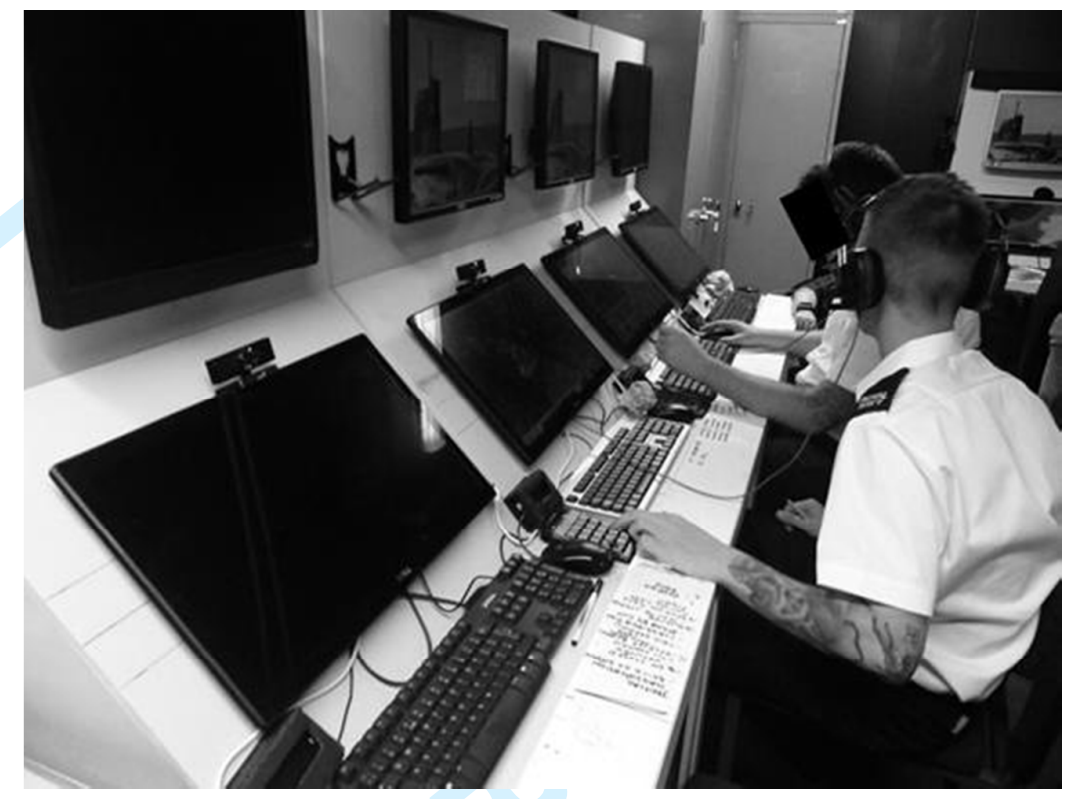

Figure 4 - Network representations which foreground the role of structure drove the design of this submarine control room simulator, which allows total flexibility in task, social and information structure to be analytically prototyped and tested.

\section{Dynamism and change}

De Greene (1980) identifies 'major conceptual problems in the systems management of ergonomics research' and notes the particular difficulties that stem from the use of static models. Lee (2001), Guastello (2002) and Sharma (2006) also express concern over the use of static models of cognition and human/machine interaction. Woods and Dekker (2000), however, put it most forcefully:

"The quickening tempo of technology change and the expansion of technological possibilities has largely converted the traditional shortcuts for access to a design process (task analysis, guidelines, verification and validation studies, etc.) into 
oversimplification fallacies that retard understanding, innovation, and, ultimately, [ergonomic' s] credibility.” (p. 272)

In Walker et al. (2009 \& 2010) we talked about emergence and the notion that simple, component-level behaviours can give rise to disproportionate, non-linear collective effects over time. We have also tried to demonstrate this feature with the road freight and logistics example shown above, whereby locally rational behaviours translated into globally irrational outcomes. The working definition put forward for the concept of emergence is "phenomenon wherein complex, interesting high-level function is produced as a result of combining simple low-level mechanisms in simple ways" (Chalmers, 1990, p.2). Like the term 'system', emergence actually describes a range of phenomenon because as "systems become more complex [...], selforganization appears at more than one level [...]. Such systems have multiple, hierarchical levels of self-organization, and calculation of system level emergent properties from the component level rapidly becomes intractable" (Halley \& Winkler, 2008 , p. 12). In other words, there is a continuum of emergence and a judgement available to be made about where the ergonomics discipline generally operates in relation to the different types, as Table 1 shows:

Table 1 - Types of emergence, the information needed in order to make a diagnosis of the system's behaviour, and tentative examples of existing methods and approaches at each level (definitions from Bar Yam, 2004).

\begin{tabular}{|l|l|l|l|}
\hline Emergence & Type & $\begin{array}{l}\text { Information needed in order to } \\
\text { make a diagnosis of the system's } \\
\text { collective behaviour }\end{array}$ & $\begin{array}{l}\text { Examples of ergonomic } \\
\text { methods }\end{array}$ \\
\hline None & Deterministic & $\begin{array}{l}\text { Knowledge of individual system } \\
\text { components sufficient to fully } \\
\text { explain global system behaviour. }\end{array}$ & $\begin{array}{l}\text { Static, ergonomic models and } \\
\text { methods such as Hierarchical } \\
\text { Task Analysis (HTA)... }\end{array}$ \\
\cline { 1 - 4 } & Type $0^{*}$ & $\begin{array}{l}\text { As for Type 0 but with additional } \\
\text { knowledge about the positions and }\end{array}$ & $\begin{array}{l}\text { Ergonomic models and } \\
\text { methods that incorporate a }\end{array}$ \\
\hline
\end{tabular}




\begin{tabular}{|c|c|c|c|}
\hline & & $\begin{array}{l}\text { dynamics of individual entities in a } \\
\text { system, this being sufficient to } \\
\text { describe the "microscopic as well as } \\
\text { macroscopic properties of the } \\
\text { system" (Bar Yam, 2004c, p. 17). }\end{array}$ & $\begin{array}{l}\text { timeline such as Operator } \\
\text { Sequence Diagrams (OSD)... }\end{array}$ \\
\hline \multirow[t]{2}{*}{ Strong } & Type 2 & $\begin{array}{l}\text { As for Type } 1 \text { but with additional } \\
\text { knowledge of possible states and } \\
\text { configurations the system can adopt. } \\
\text { "the state of one part may determine } \\
\text { (or be coupled to) the state of other } \\
\text { parts" (Bar Yam, 2004c, p. 17). }\end{array}$ & 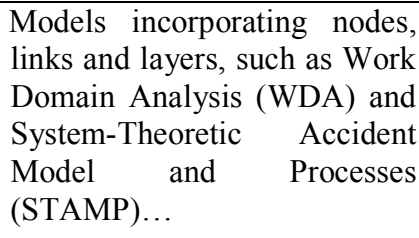 \\
\hline & Type 3 & $\begin{array}{l}\text { As for Type } 2 \text { but with additional } \\
\text { knowledge of the environment that } \\
\text { the system resides in. "This is not } \\
\text { contained in the conventional } \\
\text { discussion of properties of a system } \\
\text { as determined by the system itself" } \\
\text { (Bar Yam, 2004c, p. 17). }\end{array}$ & $\begin{array}{l}\text { Methods which use networks } \\
\text { to model how systems move } \\
\text { within a phase space, such as } \\
\text { Event Analysis for Systemic } \\
\text { Teamwork (EAST)... }\end{array}$ \\
\hline
\end{tabular}

It is possible to argue that Type 3 emergence is a key characteristic of the deeply perplexing Ergonomic problems which seem to be increasingly exposed by the fact that certain Ergonomic 'low hanging fruit' have been (and will continue to be) dealt with successfully using existing approaches. Dealing with Type 3 emergence, on the other hand, requires knowledge of individual system components (an individual, component-level view which features heavily in the discipline); knowledge of the dynamics of those components (achievable with some methods which acknowledge the role of time); states and configurations of the system (achievable with the kinds of network-based approaches shown above, and others); but also knowledge of the wider environment. This is a special, more conceptual form of environmental knowledge which needs extra clarification.

It might be more helpful to reframe the question of Type 3 emergence in more practical terms. Basically, how do you analyse systems with multiple actors, multiple relationships, multiple degrees of freedom, multiple states and multiple possible behaviours...in a tractable, time and cost efficient manner? One option is to take the 
system apart and separate it into its constituent components. This is possible but the problems with doing so are twofold. Firstly, the more one isolates key variables and controls for other extraneous factors, the less the phenomena of interest looks and behaves like the 'real' multi-dimensional problem that is attempting to be solved. Experimental control, therefore, will more frequently find itself in conflict with ecological validity. Secondly, to empirically evaluate all possible states of a truly multi-dimensional system would likely need a sample size, due to the sheer number of conditions, manipulations, and required statistical power that would exceed the human population on Earth. It is no wonder, then, that ergonomic analyses of these systems often shy away from what this multi-dimensionality really means, proceeding instead on the basis of more ad-hoc, single-case study approaches which, nevertheless, are often still labelled 'experiments' (e.g. CCRP, 2004).

An alternative approach to the conceptual problems posed by Type 3 emergence is to tackle it from the top-down (the system) instead of from the bottom-up (the components). Approaching the system top-down in terms of structure is highly beneficial, as the submarine case-study above shows, but it is possible to go further still. The central idea can be summed up by the simple cybernetic principle that: "if all the variables are tightly coupled, and if you can truly manipulate one of them in all its freedoms, then you can indirectly control all of them" (Kelly, 1994, p. 121). Thus the behaviour of individual components are not measured in isolation, rather the product of those collective behaviours are measured as a whole. Phase spaces are a tractable ergonomic approach for doing this. 
Phase spaces arise from the study of complex dynamical systems and the inadequacies of simple one dimensional time series analyses in capturing and representing their behaviour. Unlike simple time series graphs, with time on the $\mathrm{x}$ axis and one variable on the $y$-axis, phase spaces are a graphical way to analyse the time varying interactions between multiple variables. Although the resulting representation is entirely abstract it can reveal fundamental properties about the system in question. Indeed, it is quite common for prominent graphical features to have some kind of physical analogue (in the famous Lorenz example it is fluid flow changing direction, for example). Unlike physical systems, many of the variables of interest within ergonomics problems are not easily or usefully reduced to a set of fundamental equations which can be plotted into a coordinate space with complete precision. This has been resolved to some extent in related approaches like Functional Holography (Baruchi et al., 2004; 2006). As in the case of physical systems, whereby multidimensionality is reduced algebraically, here the multidimensionality can be reduced via Principal Components Analysis, or other similar means, based entirely on the structural properties of networks. By clustering individual components and having them form the principle axes of a phase space, the relationships between multiple dimensions of a system are preserved: the reduced set of dimensions still enables you to indirectly manipulate all others.

In our own research we have used a dimensionally reduced organisational 'phase space' called the NATO SAS050 model of command and control (NATO, 2007). We combined it with Social Network Analysis as a way to represent real command and control teams during a large-scale military operational field trial. To convey an idea of the scale and complexity of this study, and the challenges inherent in conducting 
an Ergonomic analysis in this domain, it can be noted that it took place (outside in poor weather conditions) in a 116 square kilometre military training area, employed a fully functioning Brigade level field headquarters, geographically dispersed Battlegroup headquarters, 73 personnel, a simulated attack and over 2500 communication exchanges. It was also not possible to interfere with any of the normal activities being performed or to extract or apply more typical behavioural measures. Combining social network analysis with an organisational phase space represented a novel way to drive out insights the stakeholders were in critical need of.

A social network is "a set of entities and actors [...] who have some type of relationship with one another." (Driskell \& Mullen, 2005, p. 58-1). Communications links between actors in the scenario were captured by the command and control system and via observation, thus meeting the stakeholder's stipulations governing our participation in this live exercise. Social network 'analysis' is about mathematically scrutinizing those relationships to discern properties that are not necessarily apparent from visual inspection of the network alone (e.g. Harary, 1994). These properties include several that related to the main dimensions of the NATO 'organisation model', or phase space, being used in this study. For example, it was established that sociometric status, a measure denoting the prominence of a node in the network based on its communications with other nodes, had good construct validity with the organisational property "decision rights". Network diameter, a measure denoting the maximum number of communication links needed to traverse the network from one side to the other, had good construct validity with the property "patterns of interaction". Network density, a measure of the average 
interconnectivity within the network, had good construct validity with the final axis called "distribution of information" (see Walker et al., 2009). Mapping social network metrics to an organisational phase space meant that an organisation as complex and dynamic as this could be positioned in the organisation model (the phase space) based on the communications taking place within it, which were straightforward to collect. The ultimate goal of this activity was to show if the organisation's position in the phase space, after considerable financial investment in new equipment and procedures, was where it should be positioned. In this particular case it was not, as Figure 5 shows.

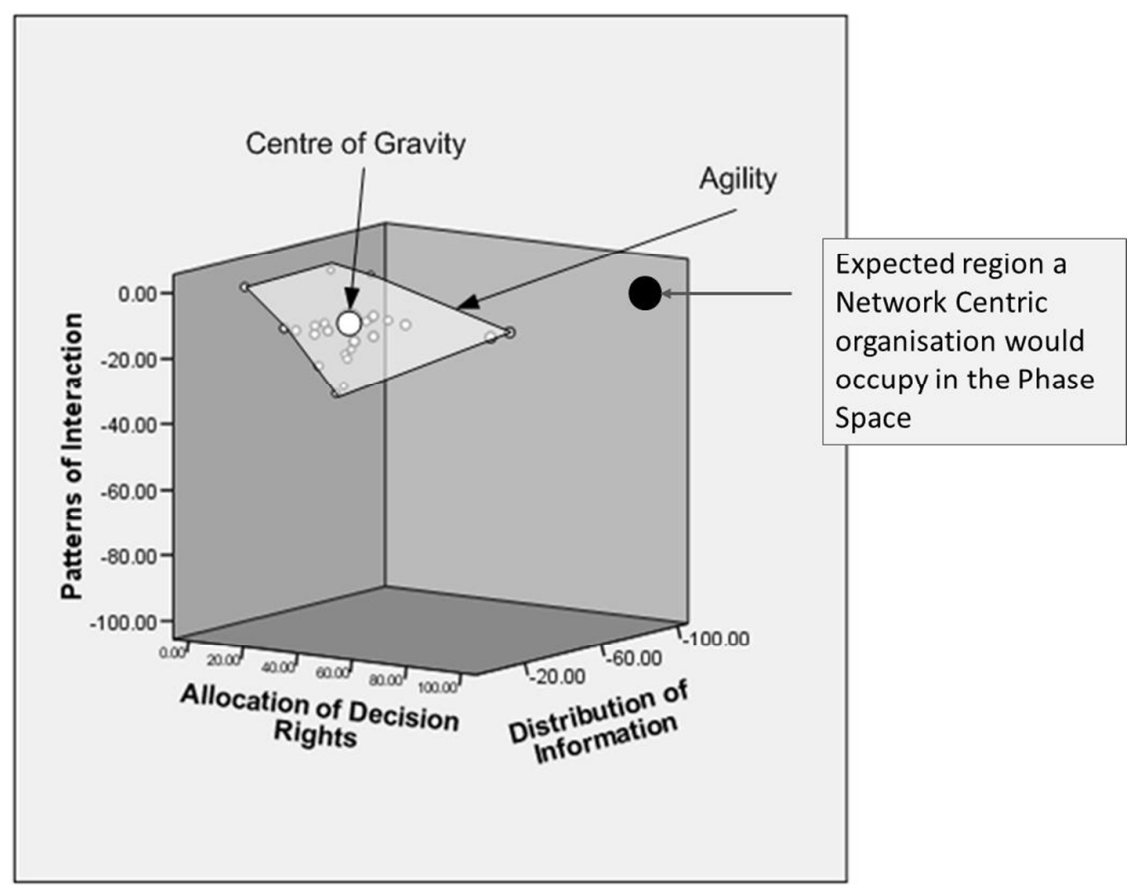

Figure 5 - A large scale military operational field trial was analysed using social network analysis and plotted into a dimensionally reduced organisational phase space. It showed that the command and control organisation was not as agile or 'net-centric' as was originally thought and this, in turn, was born out in various measures of performance. 
Different actors in this scenario needed to communicate with other actors at different times for different purposes. By analysing the social networks over successive periods of time it was possible to observe how their interconnection changed as a function of the task and the operating environment. These changes relate to a property called agility, or the "ability to reconfigure structures rapidly [..] enabled by an information environment that allows rapid reconfiguration of the underlying network and knowledge bases" (Ferbrache, 2005, p. 104). As the social networks change so the network metrics change. The range of different values these metrics describe over time says something important about how the sociotechnical system is reconfiguring itself, in particular how fast and by how much. When the changing values of the network metrics are plotted into a graph with the $\mathrm{x}$-axis representing time and the $y$-axis representing the corresponding social network metric value, the resultant time-series resembles a complex waveform. Spectral analysis methods were then be used to unpick this complex waveform into a set of constituent frequencies which provided insights into organisational agility in a very direct manner (see Walker et al., 2010). 


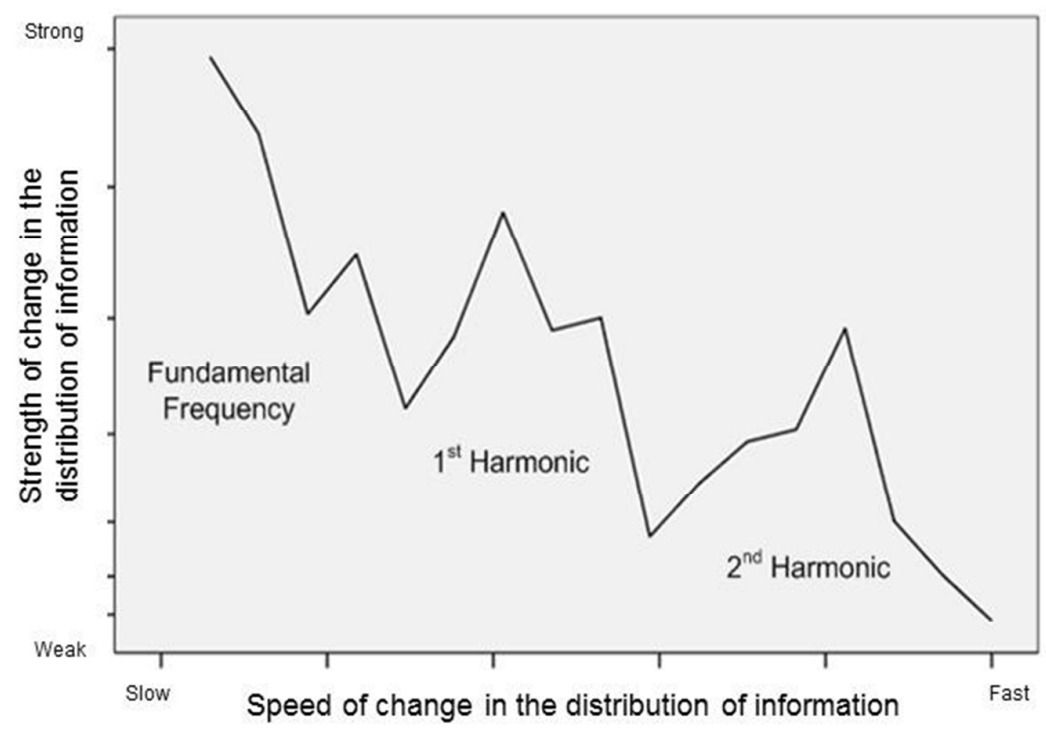

Figure 6 - Periodogram illustrating the presence of periodic changes in the distribution of information (i.e. network density) within a live military command and control case study. A pattern is obtained that approximates to first, second and third order harmonic effects.

Figure 6 shows the results of this unpicking process in a representation called a periodogram. In this application the x-axis shows the extent to which the social network is reconfiguring, the y-axis shows how quickly it is reconfiguring. In the example shown there is a strong 'fundamental frequency' of organisational reconfiguration, but weaker spikes of faster reconfigurations occurring at multiples of the fundamental frequency (these are called 'harmonics'). Patterns like these reveal something important about the sociotechnical system's dynamics. Evidence of periodicity indicates that the organization is repeatedly drawn into, or attracted, into specific locations of its phase space, revealing in turn specific configurations of that organisation which are more persistent than others. The lack of a pattern or periodicity is just as interesting. It suggests that the forces present in the environment which are driving the organization's dynamic reconfigurations might be more chaotic in nature. 
To be even more specific, clusters that form in defined areas of the phase space, and into which the organisation was repeatedly drawn (like those shown in in Figure 5) can be termed 'fixed attractors'. Fixed attractors represent something analogous to equilibrium state(s) of the system or the dominant prevailing behaviours. This does not fully describe the dynamical behaviour of the real command and control organisation under analysis, however, because many of the other points did not fall into defined clusters at all and were instead scattered widely. The organisation was thus attracted to these other points in the phase space by forces whose underlying dynamics were not stable and deterministic, but unstable and chaotic. In the parlance of complex adaptive systems these would be termed 'strange attractors'.

The presence of attractors in an organisational phase space suggests a much more fundamental source of organisational dynamics, linking in turn to a much more abstract idea of 'environment'. The fact sociotechnical systems of any kind are drawn or otherwise propelled into different regions of their phase spaces indicates that, like a ball rolling across a surface containing dips and hollows, this abstract environment possesses a defined 'causal texture' (e.g. Emery \& Trist, 1978). This is a classic sociotechnical systems concept. So is the idea that a sociotechnical system is itself part of the environment and through its actions able to influence its causal texture. We come back, then, to the idea that there are multiple interconnected pathways which are constantly moving and shifting...no predefined system layers...no predefined (static) holes in the 'Swiss Cheese'... and no possibility of detecting the things we really want to detect by focussing exclusively on the components. At least now, via phase spaces and innovative use of ergonomic 
methods, these features are able to become visibly manifest and open to inspection. In this case, the stakeholders were able to gain a much deeper understanding of what organisational agility actually meant, how to measure it, and valuable insights into process improvements targeted at shifting their position in the phase space into more desirable regions, and the ability to measure and check those improvements ongoing.

\section{Conclusions}

The aim of this paper has been to take advantage of a unique opportunity (and Special Issue) to stand back and critically examine the ergonomic paradigm and the manner in which it may have to change. Strategically it has been written that the discipline will be required to work on more high-quality, high-impact systems problems but this, in turn, requires that systems thinking remains at the forefront of ergonomics theory and practice. This does not mean a shift in the discipline's overriding philosophical stance of pragmatism. On the contrary. Theoretical issues in ergonomics science are the route along which the next generation of methods and approaches will ultimately stem. The case studies chosen in this paper have also been deliberate: although founded on sometimes obtuse, highly conceptual theories all of them were carried out at the behest of industrial clients with thorny problems that had proven resistant to existing approaches. In other words, these 'quantum concepts' have all been practically applied and without exception provided useful, cost-effective insights for real ergonomic clients. Insights which, up until this point, had alluded them. 
This paper's journey into the ergonomic paradigm has also taken us towards something nearer-term and more pressing. There is a fundamental need to match our methods to the developing nature of our ergonomic problems. Quite often, the precipitating event which leads to the engagement of ergonomic services is a problem that existing tools and techniques cannot make progress on. Increasingly, we would argue, these problems contain significant amounts of emergence for which our simple and supposedly pragmatic methods have the most trouble dealing with. Matching methods to problems will inevitably mean a much stronger systems perspective being adopted. In this regard, and compared to some other fields, ergonomics may have been too timid. Too focussed on the resolution of immediate problems by tools and techniques now ill-suited to new challenges. The answer is open to debate and will be for the discipline to decide, but journeying out into uncharted ergonomic territory we have been able to catch glimpses of what the discipline needs to do to remain relevant in the future. If we are not able to adapt to a new 'quantum world' of multi-dimensionality, colinearity, dynamism and complexity then other disciplines will do it for us. The warning from the future is that other disciplines are already revealing new ergonomic insights from the internet of things and big data, simply because they have adapted more quickly than we have. Let us be bolder. There is an opportunity for ergonomics to become a leading rather than following discipline in new scientific and engineering paradigms. After all, these new paradigms are entirely human-constructed entities, and so too are the key future challenges.

\section{Acknowledgement}


We gratefully acknowledge the assistance of Dr Miranda Cornelissen, who was involved in the brainstorming sessions and aided with ideas and transcription.

\section{References}

Alberts, D. S., Garstka, J. J. \& Stein, F. P. (1999). Network centric warfare: Developing and leveraging information superiority. Washington, DC: CCRP.

Annett, J., Duncan, K. D., \& Stammers, R. B. \& Gray, M. J. (1971). Task analysis. London: HMSO.

Ball, P. (2005). Critical mass: how one thing leads to another. London: Arrow. Baruchi, I \& Ben-Jacob, E. (2004). Functional holography of recorded neuronal networks activity. Neuroinformatics, 2(3), 333-351.

Baruchi, I., Grossman, D., Volman, V., Shein, M., Hunter, J., Towle, V. \& Ben-Jacob, E. (2006). Functional holography analysis: simplifying the complexity of dynamical networks. $\underline{\text { Chaos, } 16}, 015112$.

Bar-Yam, Y. (2004). Multiscale complexity/entropy. Advances in Complex Systems, $\underline{7}, 47-63$.

Beecham, R. and Wood, J.D. (2014). Characterising group-cycling journeys using interactive graphics. Transportation Research Part C: Emerging Technologies, 47(2), 194-206.

Bertalanffy, L. v. (1950). The theory of open systems in physics and biology. Science, 111, 23-29.

Command and Control Research Program (2004). Code of Best Practice for C2 Assessment. Washington, DC: CCRP. 
Carvajal, R. (1983). Systemic netfields: the systems' paradigm crises. Part I. Human Relations, 36(3), 227-246.

Chalmers, D.J., 1990. Thoughts on emergence [online]. Available at: http://consc.net/notes/emergence.html [Accessed 13th March 2015].

Chung, A. Z. Q. \& Shorrock, S. T. (2011). The research-practice relationship in ergonomics and human factors - surveying and bridging the gap. Ergonomics, 54(5), 413-429.

De Greene, K. B. (1980). Major conceptual problems in the systems management of human factors/ergonomics research. Ergonomics, 23(1), 3-11.

Driskell, J.E. and Mullen, B. (2005). Social network analysis. In Handbook of Human Factors and Ergonomics Methods, N.A. Stanton et al. (Eds.), pp. 58.1-58.6 (Boca-Raton, FL: CRC).

Drury, C. (2015). Human factors/ergonomics implications of big data analytics: Chartered Institute of Ergonomics and Human Factors annual lecture. Ergonomics, 58(5), 659-673.

Dul J, Bruder R, Buckle P, Carayon P, Falzon P, Marras. W. S, Wilson J.R, van der Doelen B. (2012). A strategy for human factors/ergonomics: Developing the discipline and profession Ergonomics, 55 (4), 377-395.

Emery, F. E. \& Trist E. L. (1965). The causal texture of organisational environments. Human Relations, 18 (1): 21-32.

European Aviation Safety Authority (2014). Annual Safety Review 2010. Cologne, Germany: EASA.

Evans, A.W. (2011). Fatal train accidents on Europe's railways: 1980-2009. Accident analysis and prevention, 43(1), 391-401. 
Ferbrache, D. (2005). Network enabled capability: concepts and delivery. Journal of Defence Science, 8(3), 104-107.

Guastello, S.J. (2002). Managing emergent phenomena: Nonlinear dynamics in work organizations. Mahwah, NJ: Lawrence Erlbaum Associates.

Hall, A. D. \& Fagen, R. E. (1956). Definition of system. General Systems, I.

Halley, J.D. and Winkler, D.A., 2008. Classification of emergence and its relation to self-organization. Complexity, 13 (5), 10-15.

Hancock, P.A. (1997). Essays on the Future of Human-Machine Systems. Banta: Eden Prairie: MN.

Harary, F. (1994). Graph Theory. Reading, MA: Addison-Wesley.

Harvey, C. and Stanton, N. A. (2014) Safety in System-of-Systems: ten key challenges. Safety Science, 70, 358-366.

Hubler, A. W. (2005). Predicting complex systems with a holistic approach: the 'throughput' criterion. Complexity, 10(3), 11-16.

Hubler, A. W. (2006). Information engines: converting information into energy. Complexity, 12(2), 10-12.

Hubler, A. W. (2007). Understanding complex systems. Complexity, 12(5), 9-11.

Huxley, A. T. (1932). Brave new world. New York, NY: Harper Collins.

IEA (2015). What is ergonomics: definition and domains of ergonomics. Available at http://www.iea.cc/whats/

Kellmereit, D. \& Obodovski, D. (2013). The silent intelligence: the internet of things. San Francisco, CA: DnD Ventures

Kelly, K., 1994. Out of control: The new biology of machines, social systems, and the economic world. New York: Purseus. 
Kirwan, B (1997) The validation of three human reliability quantification techniques THERP, HEART and JHEDI: Part III - Practical aspects of the usage of the techniques. Applied Ergonomics, 28(1), 27-39.

Kirwan, B. (1998) Human error identification techniques for risk assessment of high risk systems - Part 1: Review and evaluation of techniques. Applied Ergonomics, 29(3), 157-177.

Kirwan, B., Kennedy, R., Taylor-Adams, S. and Lambert, B. (1997). The validation of three human reliability quantification techniques, THERP, HEART and JHEDI: Part II - results of validation exercise. Applied ergonomics, 28 (1), $17-25$.

Leavitt, H. J. (1951). Some effects of certain communication patterns on group performance. Journal of Abnormal and Social Psychology, 46, 38-50.

Lee, J. D. (2001). Emerging challenges in cognitive ergonomics: managing swarms of self-organising agent-based automation. Theoretical Issues in Ergonomics Science, 2(3), 238-250.

Marcovici, M. (2014). The internet of things. Hamburg: Books on Demand Miller, M. (2015). The internet of things: how smart TVs, smart cars, smart homes, and smart cities are changing the world. Indianapolis, IN: QUE

Mitchell, V. L. \& Nault, B. R. (2003). The emergence of functional knowledge in sociotechnical systems. Haskayne School of Business, University of Calgary.

Monge, P. R. \& Contractor, N. S. (2003). Theories of communication networks. Oxford: Oxford University Press.

NATO (2007). RTO-TR-SAS-050 Exploring New Command and Control Concepts and Capabilities. Report: RTO-TR-SAS-050 AC/323(SAS-050)TP/50. 
NATO. Available at: http://www.rta.nato.int/Pubs/RDP.asp?RDP=RTO-TRSAS-050

Nijkamp, P., Pepping, G., Banister, D. (1997). Telematics and Transport Behaviour. Springer-Verlag, Berlin.

Ogden, G.C. (1987). Concept, knowledge and thought. Annual Review of Psychology, 38, 203-227.

Pugh, D. S., Hickson, D. J., Hinings, C. R. \& Turner, C. (1968). Dimensions of organisation structure. Administrative Science Quarterly, 13(1), 65-105.

Rasmussen, J. (1997). Risk management in a dynamic society: a modelling problem. Safety Science, $27,183-213$.

Rifkin, J. (2014). The zero marginal cost society. New York, NY: Palgrave Macmillan.

Roetzheim, W. (2007). Why things are: how complexity theory answers life's toughest questions. Jamul, CA: Level 4.

Ropohl, G. (1999). Philosophy of socio-technical systems. Society for Philosophy and Technology, 4(3), 1-10.

Salmon, P. M. \& Lenne, M. G. (2015). Miles away or just around the corner? Systems thinking in road safety research and practice. Accident Analysis and Prevention, 74, 243-249.

Salmon, P. M., Walker, G. H. \& Stanton, N. A. (In Press). Broken components versus broken systems: why it is systems not people that lose situation awareness. Cognition, Technology \& Work

Salmon, P., Stanton, N., \& Walker, G., \& Baber, C. (2005). Integrating human factors methods: the HF methods matrix. Human Computer Interaction International (HCII) Conference, 22-27 July, Las Vegas, US. 
Schumpeter, Joseph A. (1994) [1942]. Capitalism, Socialism and Democracy. London: Routledge. pp. 82-83.

Sharma, S., 2006. An exploratory study of chaos in human-machine system dynamics. IEEE Transactions on Systems, Man, and Cybernetics-Part A: Systems and Humans, 36 (3), 319-326.

Smolan, R. \& Erwitt, J. (2012). The human face of big data. Television documentary. Against All Odds Productions.

Stanton, N. A. (2014) Representing Distributed Cognition in Complex Systems: How a submarine returns to periscope depth. Ergonomics, 57 (3), 403-418.

Stanton, N. A. \& Bessell, K. (2014). How a submarine returns to periscope depth: analysing complex socio-technical systems using cognitive work analysis. Applied Ergonomics, 45(1), 110-125.

Stanton, N. A., Baber, C. and Harris, D. (2008) Modelling Command and Control: Event Analysis of Systemic Teamwork. Ashgate: Aldershot.

Stanton, N. A., Salmon, P. M., Rafferty, L., Walker, G. H., Baber, C. \& Jenkins, D. P (2013). Human Factors Methods: A Practical Guide for Engineering and Design. (2nd Edition). Farnham, UK: Ashgate.

Stanton, N. A., Salmon, P. M. and Walker, G. H. (2015) Let the Reader Decide: A Paradigm Shift for Situation Awareness in Sociotechnical Systems. Journal of Cognitive Engineering and Decision Making. 9(1), 44-50.

Stanton, N. A., Salmon, P. M., Walker, G. H., Baber, C. \& Jenkins, D. P (2005) Human Factors Methods: A Practical Guide for Engineering and Design. Farnham, UK: Ashgate.

Toffler, A. (1981). Future shock: the third wave. New York: Bantam. Toffler, A. (1980). The third wave. London: Pan. 
Trafimow, D. \& Marks, M. (2015). Editorial. Basic and Applied Social Psychology, $\underline{37}(1), 1-2$.

Trist, E. L. (1978). On socio-technical systems. In, Pasmore, W. A. \& Sherwood, J.

J. (Eds.), Sociotechnical systems: A sourcebook. San Diego, CA:

University Associates.

Venda, V. F. (1995). Ergodynamics: theory and applications. Ergonomics, 38(8), 1600-1616.

Waldrop, M. M. (1992). Complexity: the emerging science at the edge of order and chaos. New York: Simon \& Schuster.

Walker, G. H. \& Strathie, A. (2016). Big data and ergonomics methods: a new paradigm for tackling strategic transport safety risks. Applied Ergonomics, $\underline{53}, 298-311$

Walker, G. H., Stanton, N. A. \& Salmon, P. M. (2015). Human factors in automotive engineering and design. Farnham: Ashgate.

Walker, G. H. \& Manson, A. (2014). Telematics, Urban Freight Logistics and Low Carbon Road Networks. Journal of Transportation Geography, 37, 74-81.

Walker, G. H, Stanton, N. A., Salmon, P. M. \& Jenkins, D. P. (2010). Command and control: the sociotechnical perspective. Farnham, UK: Ashgate.

Walker, G. H., Stanton, N. A., Salmon, P. M., Jenkins, D. P. \& Rafferty, L. (2010). Translating concepts of complexity to the field of ergonomics. Ergonomics, $\underline{53}(10), 1175-1186$.

Walker, G. H., Stanton, N. A., Revell, K., Rafferty, L., Salmon, P. M. \& Jenkins, D. P. (2009). Measuring dimensions of command and control using social network analysis: extending the NATO SAS-050 model. International Journal of Command and Control, 3(2), 1-47. 
Watts, D. J. \& Strogatz, S. H. (1998). Collective dynamics of 'small-world' networks. Nature, 393(4), 440-442.

Wilson, J. R. \& Corlett, N. (2005). Evaluation of human work: third edition. BocaRaton, FL: CRC.

Woods, D.D. and Dekker, S. (2000). Anticipating the effects of technological change: a new era of dynamics for human factors. Theoretical Issues in Ergonomics Science, 1 (3), 272-282. 